\title{
Significantly reduced expression of the proteoglycan decorin in Alzheimer's disease fibroblasts
}

\author{
Enrique Brandan, Francisco Melo, María García, Maribel Contreras
}

\begin{abstract}
Aims-To investigate whether proteoglycan synthesis is altered in skin fibroblasts in patients with Alzheimer's disease compared with normal subjects.

Methods-Cell lines obtained from donors with Alzheimer's disease and healthy controls were incubated with radioactive sulphate. The proteoglycans synthesised were determined and analysed by chromatographic, sodium dodecyl sulphatepolyacrylamide gel electrophoresis (SDSPAGE) and glycosaminoglycans-lyase treatment. The amount of decorin synthesised by each cell line was quantified using western blot analysis. Transcripts for human decorin were determined using northern blot analysis.
\end{abstract}

Results-No significant changes in total sulphate incorporation and glycosaminoglycan (GAG) composition were detected in the incubation media of these cells. However, chromatographic and SDS-PAGE analysis of the proteoglycans secreted by the cell lines showed that a dermatan sulphate proteoglycan of 150125 kilodaltons was substantially reduced in Alzheimer's disease fibroblasts. The molecular characteristics of this proteoglycan correspond to decorin. Western blot analysis indicated that decorin was reduced in Alzheimer's disease incubation medium compared with normal medium. Northern blotting indicated that in Alzheimer's disease fibroblasts decorin transcripts were significantly reduced compared with normal fibroblasts. Glypican concentrations, a cell surface heparan sulphate proteoglycan, remained the same.

Conclusions-These results strongly suggest that the expression and synthesis of decorin is affected in Alzheimer's disease skin fibroblasts.

(f Clin Pathol: Mol Pathol 1996;49:M351-M356)

Keywords: proteoglycans, decorin, cell adhesion, Alzheimer's disease, fibroblasts.

The possible role of extracellular matrix (ECM) components in some neurological diseases, including Alzheimer's disease, has come under increasing scrutiny. ${ }^{12}$ In Alzheimer's disease several proteoglycans and ECM molecules have been associated with neuritic plaques. ${ }^{2-4}$ The direct interaction of heparan sulphate pro- teoglycans with the $\beta$-amyloid precursor protein ( $\beta$-APP), an essential component of neuritic plaques, has been shown in vitro ${ }^{5}$ and in vivo ${ }^{6}$ after infusions of $\beta$-APP plus a specific heparan sulphate proteoglycan. This suggests that heparan sulphate proteoglycans are key elements in the formation of the amyloid plaques that are characteristic of Alzheimer's disease, providing that the nucleation events, needed for facilitation of protein conformations, induce fibril formation and/or decrease amyloid susceptibility to proteolysis. Changes in proteoglycan synthesis may promote neurofibrillary tangles and cerebrovascular amyloid deposition.

On the other hand, several biochemical changes in non-neuronal tissue have been shown in Alzheimer's disease. ${ }^{7-9}$ Cultured fibroblasts from familial Alzheimer's disease were less able to adhere to substrata than agematched healthy control fibroblasts. ${ }^{10} 11$ The cell adhesion process is the result of several interactions between molecules present at the cell surface and in the ECM; among the cell surface receptors, integrins and proteoglycans are the most well known, ${ }^{12-14}$ whereas molecules in the ECM, such as laminin, fibronectin, and several types of proteoglycans, have been reported to participate in the adhesion process. ${ }^{15}$ A previous report evaluated the proteoglycan composition of isolated fibroblasts from Alzheimer's disease and found a small increase in sulphate incorporation into proteoglycans compared with normal controls. ${ }^{16}$ However, the analysis was mainly focused on glycosaminoglycan (GAG) composition rather than the characteristics of intact proteoglycans. Therefore, we decided to evaluate and characterise the proteoglycans synthesised and secreted by fibroblasts from patients with Alzheimer's disease, and to compare the findings with those from healthy controls.

\section{Methods}

The following material were purchased: $\mathrm{Na}_{2}{ }^{35} \mathrm{SO}_{4}$ carrier free was obtained from New England Nuclear, Boston, Massachusetts, USA. $\left[{ }^{32} \mathrm{P}\right]$-dCTP $(6000 \mathrm{Ci} / \mathrm{mmol})$ was obtained from Amersham, Buckinghamshire, England. Chondroitinase ABC lyase, chondroitinase AC lyase, benzamidine hydrochloride, DEAE-Sephacel and Sepharose CL-6B were obtained from Sigma Chemical Co, St. Louis, Missouri, USA. Heparitinase was purchased from Miles Laboratories, Napierville, Illinois, USA. Polyclonal rabbit antiserum 
Table $1 P^{55}$ SJ-Sulphate incorporation into proteoglycan and glycosaminoglycan distribution in normal and Alzheimer's fibroblasts

\begin{tabular}{|c|c|c|c|c|}
\hline & \multicolumn{2}{|l|}{ Normal } & \multicolumn{2}{|c|}{ Alzheimer's disease } \\
\hline & $A G 4444$ & $A G 6010$ & $A G 4401$ & $A G 5770$ \\
\hline \multicolumn{5}{|l|}{ 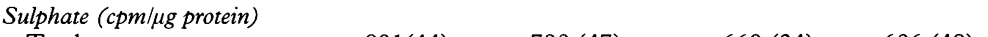 } \\
\hline Total & $891(44)$ & $790(47)$ & $669(34)$ & $606(48)$ \\
\hline PI-PLC released & $213(13)$ & $197(31)$ & $296(24)$ & $286(42)$ \\
\hline \multicolumn{5}{|l|}{$G A G(\%)$} \\
\hline Heparan sulphate & $16.0(3.5)$ & $14.4(2.6)$ & $16.1(2.7)$ & $14.4(3.3)$ \\
\hline $\begin{array}{l}\text { Chondroitin and dermatan } \\
\text { sulphate }\end{array}$ & $79.5(5.1)$ & $82.0(5.5)$ & $73.4(5.1)$ & $68.7(4.3)$ \\
\hline Chondroitin sulphate & $12.1(3.1)$ & $12.8(4.3)$ & $16.4(3.9)$ & $12.7(3.1)$ \\
\hline
\end{tabular}

The values correspond to the mean (SD) radioactivity of five flasks of each line. PI-PLC treatment comprised incubation of each plate with 2.5 units/ml PI-PLC, as described before.$^{20}$ Radioactivity is expressed in $\mathrm{dpm} / \mu \mathrm{g}$ protein.

against decorin was a generous gift of Professor Hans Kresse (University of Munster, Germany). Human decorin cDNA was a kind gift of Dr Tom Krusius (University of Helsinki, Finland).

\section{CELL LINES}

Skin fibroblasts from subjects with Alzheimer's disease and age-matched controls were obtained from the Human Mutant Cell Repository, Institute for Medical Research, Camden, New Jersey, USA. These were AG4444 and AG6010 from two normal subjects aged 62 and 63 years of age, and AG4401, AG5809, and AG5770 from three subjects with familial Alzheimer's disease aged 53, 63, and 70 years, respectively. In these last two cases, Alzheimer's disease was confirmed at necropsy from

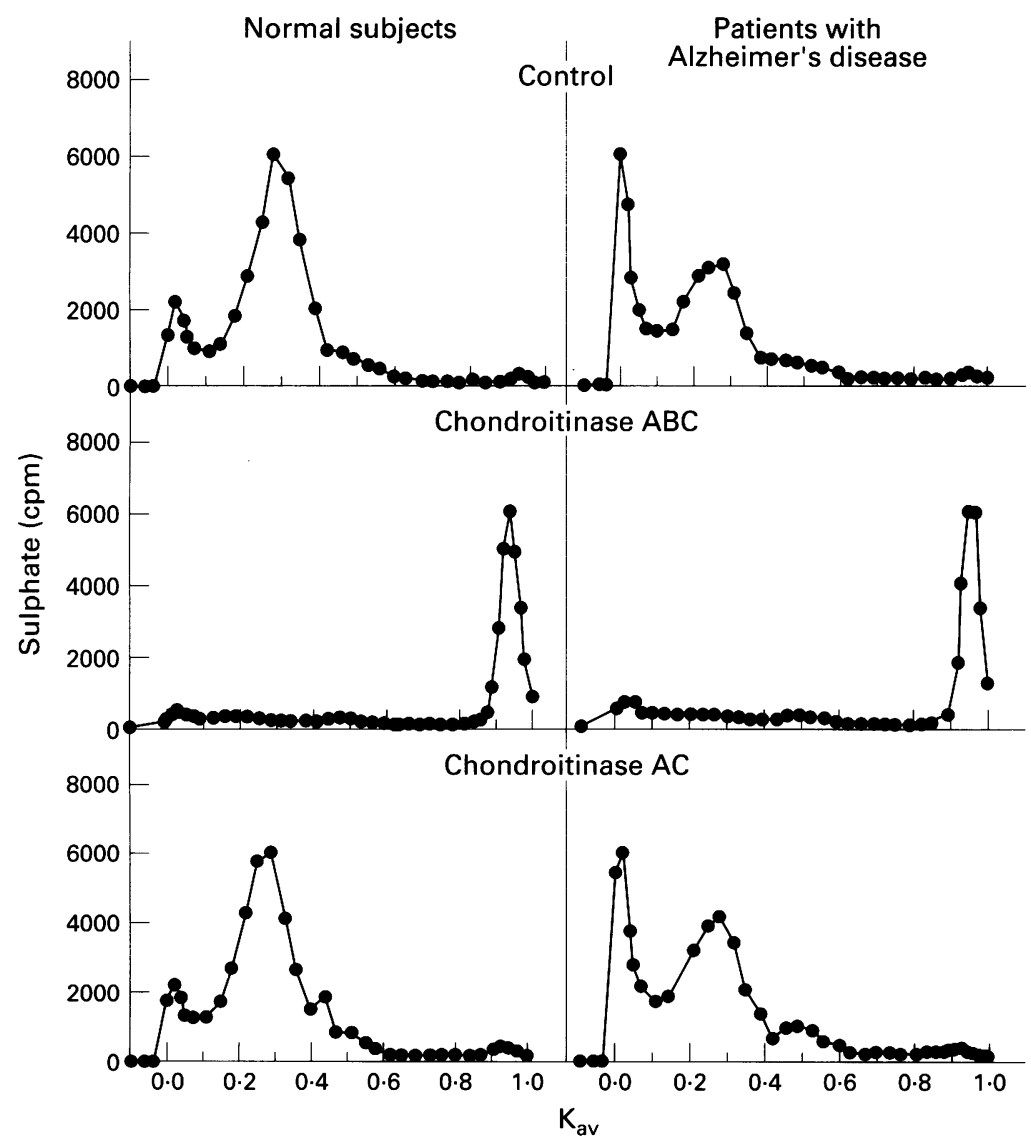

Figure 1 Chromatographic profiles of secreted proteoglycans by Alzheimer's and normal fibroblasts. Fibroblasts from normal (AG6010) and Alzheimer's disease (AG5770) were labelled with radioactive sulphate and the incubation media collected. Aliquots equivalent in $C P C$-precipitable counts were fractionated on Sepharose $C L-6 B$ and radioactivity determined. Similar results were found when the corresponding cell lines were analysed. brain tissue by the presence of Alzheimer's disease plaques. All the cell lines used presented a normal diploid karyotype. Cells were studied at passage 10 through 14. Previous studies have indicated that Alzheimer's disease fibroblasts do not age in culture more rapidly than cells from age-matched controls. ${ }^{17}$ Fibroblasts were twice cultured in Eagle's minimum essential medium with essential and non-essential vitamins and amino acids, $15 \%$ fetal calf serum, penicillin $(100 \mathrm{U} / \mathrm{ml})$ and streptomycin $(100$ $\mu \mathrm{g} / \mathrm{ml}$ ).

\section{PROTEOGLYCAN LABELLING}

Dishes $80 \mathrm{~cm}^{2}$ containing a confluent monolayer of each cell line and seeded at a constant density of $1 \times 10^{4}$ cells $/ \mathrm{cm}^{29}{ }^{18}$ for six hours, ${ }^{10}{ }^{11}$ were radiolabelled in the presence of $10 \mu \mathrm{Ci} / \mathrm{ml}$ of ${ }^{35} \mathrm{~S}$-sulphate for 18 hours. The medium was removed and dialysed with 2 litres of $10 \mathrm{mM}$ TRIS- $\mathrm{HCl}, \mathrm{pH} 7,4,0.1 \mathrm{M} \mathrm{NaCl}$, including protease inhibitors at $4^{\circ} \mathrm{C}$. The samples were concentrated in a Amicon filtration system and separated on SDS-PAGE and exposed to $x$-ray film, as described before. ${ }^{19}$ The recovery of the sulphated material after dialysis and concentration ranged between 80 and $87 \%$. Chondroitinase $\mathrm{ABC}, \mathrm{AC}$, and heparitinase treatments of labelled proteoglycans obtained from the cell cultures were done exactly as described before. ${ }^{20}$ Glypican was determined after release from the fibroblast surface by phosphatidylinositol-specific phospholipase C (PI-PLC), as described before. ${ }^{20}$

\section{GEL FILTRATION CHROMATOGRAPHY}

The radiolabelled samples were concentrated in a small DEAE-Sephacel column equilibrated in the above buffer; bound material was eluted with the same buffer containing $1.0 \mathrm{M}$ $\mathrm{NaCl}$ and then fractionated on analytical Sepharose CL-6B $(1.0 \times 100 \mathrm{~cm})$ prepared in $1 \%$ SDS, $0.1 \mathrm{M} \mathrm{NaCl}$, and $50 \mathrm{mM}$ TRIS- $\mathrm{HCl}$ buffer, $\mathrm{pH} 8.0$. Samples $(0.5 \mathrm{ml})$ were applied to the column together with previously fractionated Blue Dextran (2000) and Phenol Red, to mark void and total volumes, respectively. Columns were eluted at a flow rate of 5.0 $\mathrm{ml} /$ hour and effluent fractions of $1.0 \mathrm{ml}$ were collected and counted for radioactivity.

WESTERN BLOT ANALYSIS

Incubation medium obtained from normal and Alzheimer's disease fibroblasts was concentrated in Amicon and incubated with chondroitinase $\mathrm{ABC}$, followed by electrophoresis on $8 \%$ polyacrylamide gel; proteins were transferred to nitrocellulose, incubated in Blotto $(20 \mathrm{mM}$ TRIS- $\mathrm{HCl}, \mathrm{pH} 7.4,0.1 \mathrm{M} \mathrm{NaCl}, 5 \%$ non-fat dry milk) at room temperature to block non-specific binding, and incubated with rabbit anti-decorin antiserum (1 in 100 dilution in Blotto). ${ }^{21}$ The bound antibody was visualised with affinity purified phosphatase alkaline conjugated goat anti-rabbit IgG. 

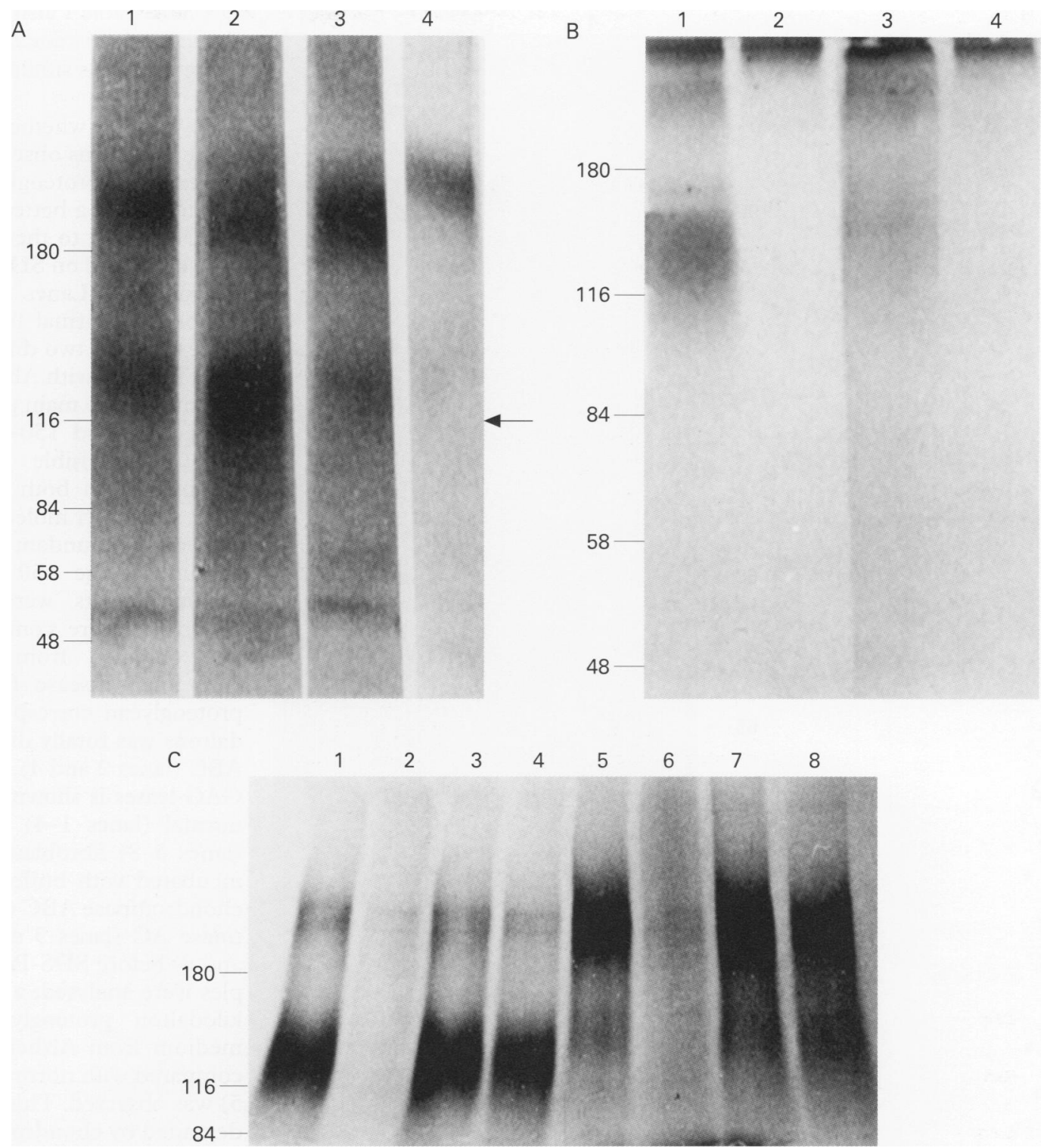

Figure 2 Diminished secretion of a dermatan sulphate proteoglycan by Alzheimer's disease fibroblasts compared with normal fibroblasts. (A) Normal (1, AG6010; 2, AG4444) and Alzheimer's disease (3, AG5770; 4, AG4401) fibroblasts were incubated with radioactive sulphate and the secreted media equivalent to the same amount of proteins were separated on SDS-PAGE. The arrow indicates the absence of a 150-125 kilodalton proteoglycan. (B) Normal (lanes 1 and 2, AG6010) and Alzheimer's disease (AG5809, 3 and 4) fibroblasts were incubated with radioactive sulphate and analysed as explained in A. Equivalent aliquots were treated with condroitinase ABC (lanes 2 and 4 ) or buffer alone (lanes 1 and 3). (C) Normal (lanes 1-4;AG4444) and Alzheimer's disease (lanes 5-8; AG5770) media were concentrated and an equivalent amount of sulphate (cpm) precipitable by CPC were treated with buffer alone (lanes 1 and 5); chondroitinase $A B C$ (lanes 2 and 6); chondroitinase $A C$ (lanes 3 and 7) or heparitinase (lanes 4 and 8) before SDS-PAGE.

RNA ISOLATION AND NORTHERN BLOT ANALYSIS Total RNA from normal and Alzheimer's disease fibroblasts was isolated, as described before. ${ }^{22}$ Total RNA was fractionated in $1 \%$ agarose-formaldehyde gels and transferred to Hybond-N membranes. A human decorin cDNA probe was radiolabelled by oligonucleotide random primer extension. Prehybridisation was carried out for three hours at $50^{\circ} \mathrm{C}$ in the presence of $5 \times \operatorname{SSPE}(0.18 \mathrm{M} \mathrm{NaCl}, 0.01$ $M$ sodium phosphate, $1 \mathrm{mM}$ EDTA, $\mathrm{pH}$ 7.7), $1 \%$ SDS, $10 \%$ dextran sulphate, $5 \times$ Denhardt's solution and $0.1 \mathrm{mg} / \mathrm{ml}$ of single stranded salmon DNA. Hybridisation was carried out overnight at $44^{\circ} \mathrm{C}$ in the above solution containing $1 \times 10^{6} \mathrm{cpm} / \mathrm{ml}$ of the ${ }^{32} \mathrm{P}$-labelled probe. Blots were washed twice at $50^{\circ} \mathrm{C}$ in 100 $\mathrm{ml}$ of $2 \times \mathrm{SSPE}$, and three washes of $50 \mathrm{ml}$ of $0.5 \times \mathrm{SSPE}, 0.1 \% \mathrm{SDS}$ for five minutes. Blots were exposed at a temperature of $-30^{\circ} \mathrm{C}$.

\section{Results}

Total sulphate incorporation into proteoglycans was determined in the incubation media obtained from two confluent Alzheimer's disease fibroblast cell lines and after comparison with two normal age-matched fibroblast cell lines. Table 1 shows no significant difference in total incorporation. Analysis of GAG composition of these media treated with heparitinase, chondroitinase $\mathrm{ABC}$, and chondroitinase $\mathrm{AC}$ also indicated that no important differences existed between these two groups of cell lines. However, when samples obtained from each group were fractionated on Sepharose CL-6B, a different chromatographic profile was observed (fig 1). The radiolabelled material from normal fibroblasts shows two main peaks, a small one with a $\mathrm{K}_{\mathrm{av}}$ close to the $\mathrm{V}_{\mathrm{o}}$, and a large one eluting with a $\mathrm{K}_{\mathrm{av}}$ of 0.3 . An inverse relation was found when the material 


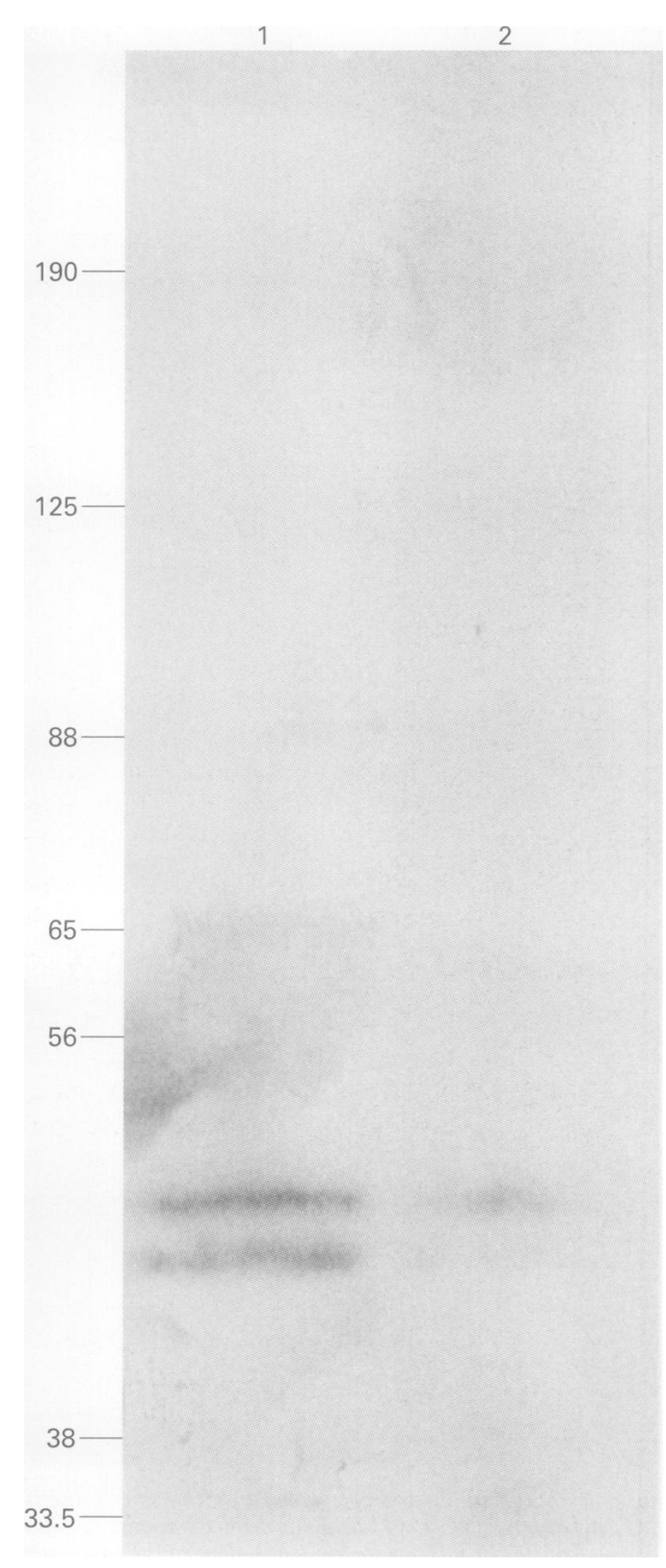

Figure 3 Alzheimer's disease fibroblasts secrete reduced amount of decorin compared with normal fibroblasts. Incubation media from normal (lane 1, AG6010) and Alzheimer's disease (lane 2, AG5770) fibroblasts were concentrated and incubated with chondroitinase $A B C$ to degrade the dermatan suphate chain and followed by SDS-PAGE. The proteins were transferred to nitrocellulose and incubated with antibodies against decorin. The characteristic doublet ( 48 and 43 kilodaltons) is shown.

obtained from Alzheimer's disease fibroblasts was fractionated on the same column. The first peak increased with a concomitant decrease in the second one. Analysis of the GAG composition showed that both peaks were sensitive to chondroitinase $\mathrm{ABC}$, but chondroitinase $\mathrm{AC}$ treatment did not alter the chromatographic pattern (fig 1). The first peak probably corresponded to biglycan whereas the second was probably decorin. Heparitinase and/or nitrous acid treatment of both materials degraded between 10 and $15 \%$ of the material from normal and Alzheimer's disease fibroblasts (data not shown). The same results were found when proliferating fibroblasts were analysed. These results suggest that the proteoglycans synthesised and secreted by these cells correspond mainly to dermatan sulphate prote- oglycans. Table 1 also shows that the amount of glypican, determined after PI-PLC treatment of the cells, was similar in all the cell lines studied.

To visualise whether the different chromatographic patterns observed corresponded to the presence of proteoglycans of different sizes, and to obtain a better separation, the samples corresponding to the same amount of protein were separated on SDS-PAGE and detected by fluorography Lanes 1 and 2 (fig 2A) correspond to normal fibroblasts; lanes 3 and 4 correspond to two different cell lines obtained from patients with Alzheimer's disease. In normal media two main proteoglycans of 280-220 kilodaltons and 150-125 kilodaltons, respectively, were visible. However, in the media obtained from both Alzheimer's disease cell lines, the higher molecular weight proteoglycan was more abundant with a relatively small amount of the 150-125 kilodalton protein. Similar results were found when normal fibroblasts were compared with another cell line obtained from patients with familial Alzheimer's disease (fig $2 \mathrm{~B}$, lanes 1 and 3 ). The proteoglycan corresponding to 150-125 kilodaltons was totally digested by chondroitinase ABC (lanes 2 and 4). The sensitivity to several GAG lyases is shown in fig 2C. Samples from normal (lanes 1-4) and Alzheimer's disease (lanes 5-8) fibroblast incubation media were incubated with buffer alone (lanes 1 and 5), chondroitinase ABC (lanes 2 and 6), chondroitinase AC (lanes 3 and 7) or heparitinase (4 and 8) before SDS-PAGE. When control samples were analysed, a decrease in the 150-125 kilodalton proteoglycan in the incubation medium from Alzheimer's disease fibroblasts compared with normal fibroblasts (lanes 1 and 5) was observed. This proteoglycan was totally degraded by chondroitinase ABC (lanes 2 and 6 ), but was resistant to chondroitinase AC and heparitinase treatments (lanes 3 and 4; 7 and 8). These results suggest that in Alzheimer's disease fibroblasts the proteoglycan of 150-125 kilodaltons, which contains dermatan sulphate GAGs, is reduced. The characteristics of this proteoglycan correspond to those of decorin. ${ }^{23}$ Thus the 280-220 kilodalton proteoglycan corresponds to biglycan whereas the 150-125 kilodalton corresponds to decorin. The same result was observed in proliferating fibroblasts, suggesting that the decrease observed in the amount of decorin is independent of the proliferative state of the cells.

To confirm that the synthesis of decorin was diminished in Alzheimer's disease fibroblasts, we determined the amount of decorin in the incubation media from normal and Alzheimer's disease fibroblasts. Samples were concentrated and separated on SDS-PAGE after chondroitinase ABC treatment. The separated proteins were transferred to a nitrocellulose membrane and incubated with antiserum against rat decorin, followed by a second antibody conjugated with alkaline phosphatase to reveal the core protein. Figure 3 (lane 1) shows that normal fibroblasts synthesise and secrete a much higher decorin concentration than Alzheimer's disease fibroblasts (lane 2), as 


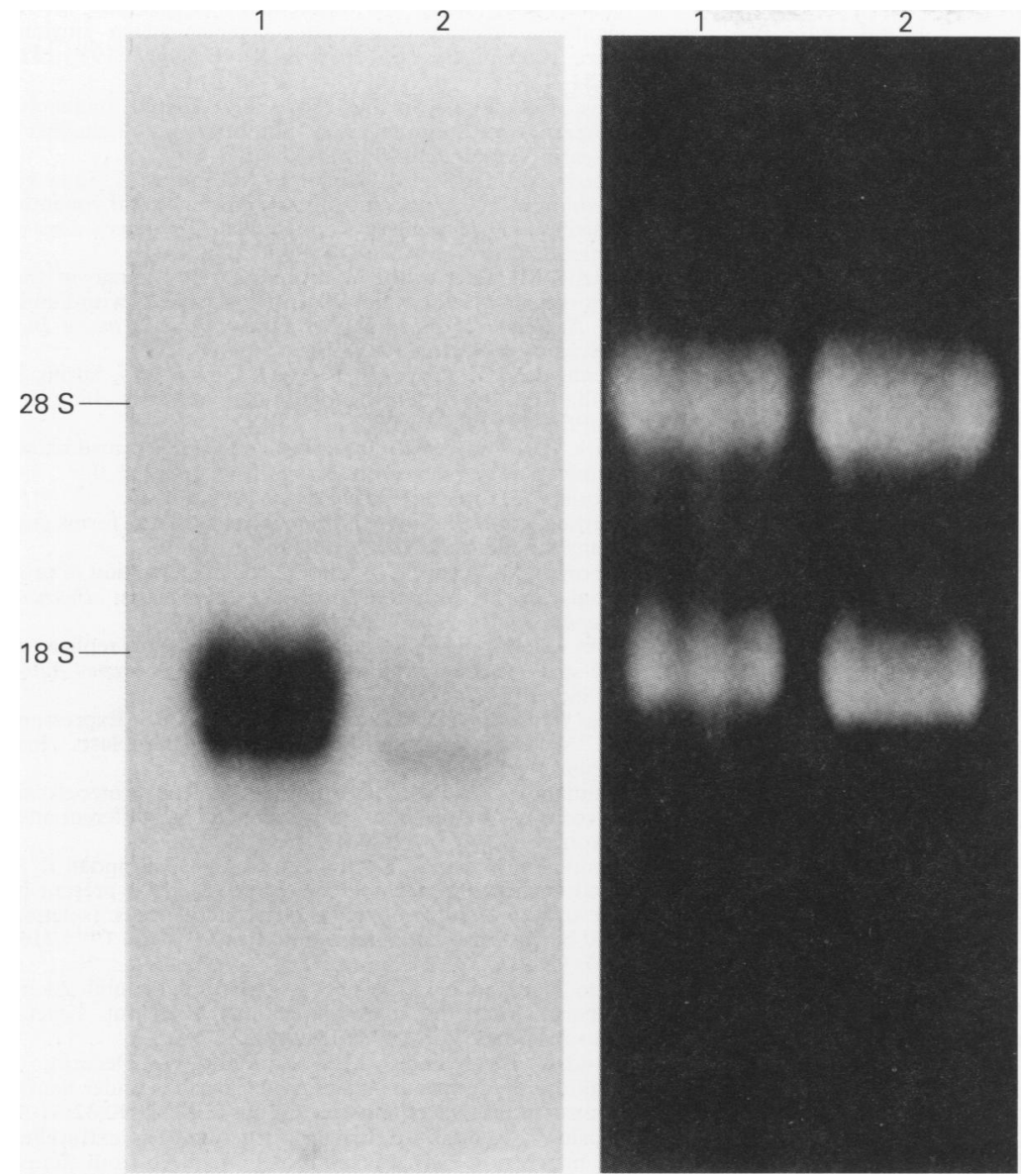

Figure 4 Alzheimer's disease fibroblasts show a reduced number of transcripts for decorin. Normal (lane 1, AG6010) and Alzheimer's disease (lane 2, AG5770) fibroblasts were cultured to confluence and total RNA was isolated. The left panel shows northern blotting using human decorin as a probe; the right panel shows ethidium bromide staining of the gel.

shown by the appearance of the characteristic doublet of 48 and 43 kilodaltons seen in human decorin core protein. ${ }^{24}$ Similar results were found when the other cell line of Alzheimer's disease was analysed. Decorin was not detected in detergent cell extracts obtained from normal and Alzheimer's disease fibroblasts (data not shown).

Finally, the concentrations for decorin messenger RNA in normal and Alzheimer's disease fibroblasts were determined. Total RNA was isolated from both types of fibroblast. Blot hybridisation analysis of these RNAs, using a cDNA against human decorin, indicates that normal human fibroblasts express transcripts of 1.6 and 1.9 kilobases (fig 4, lane 1), as described before, ${ }^{23}$ but these transcripts are much reduced in Alzheimer's disease fibroblasts (fig 4, lane 2). The ethidium bromide staining indicates that equal amounts of total RNA were fractionated. Similar results were observed with the other Alzheimer's disease cell lines (data not shown).

\section{Discussion}

Analysis of the proteoglycan described in this study shows that it corresponds to decorin, a dermatan sulphate proteoglycan. ${ }^{24}$ The diminished presence of decorin in the incubation medium of Alzheimer's disease fibroblasts seems to be specific and was observed in both cell lines independent of their proliferative state. No significant changes were detected in the total incorporation of sulphate into proteoglycan nor in the synthesis of glypican, a membrane bound heparan sulphate proteoglycan. ${ }^{20}$ Similar concentrations of the $250-220$ kilodalton proteoglycan were detected in all the cell lines evaluated. The size of this proteoglycan and total sensitivity to chondroitinase $A B C$ and resistance to chondroitinase AC treatment suggest that it is biglycan. ${ }^{25}$ Decreased decorin concentration seems to reflect low concentrations of messenger RNA, as determined in northern blot analysis.

Decorin is a proteoglycan present in the ECM of several tissues, including blood vessel walls, tendon, sclera, skeletal muscle as well as other interstitial tissues. ${ }^{1922} 26$ Decorin can interact with several ECM molecules, such as collagen types I, Vl, and XIV, fibronectin, and transforming growth factor- $\beta$ (TGF- $\beta$ ), ${ }^{27-30}$ suggesting that this proteoglycan is a key molecule for ECM organisation and for the binding and/or presentation of soluble factors to the cell. The adhesion of Alzheimer's disease fibroblasts from patients with familiar Alzheimer's disease is significantly suppressed compared with age-matched controls. ${ }^{10}{ }^{11}$ Because there are multiple binding sites for ECM molecules present on the decorin molecule, an altered ECM could receive deposits from the Alzheimer's disease fibroblasts, which would affect the normal interaction with the ECM receptors on the cell surface. ${ }^{12}{ }^{14}$ Furthermore, in those experiments where adhesion of the fibroblasts was reduced, changes in the arrangement of cytoskeletal vimentin were also observed..$^{10}{ }^{11}$ Because changes in the expression of surface proteoglycans strongly influence cytoskeletal organisation, ${ }^{31}$ altered synthesis of decorin, as shown in this study, may directly affect the interaction between the cell and the ECM, changing the intracellular arrangement of the cytoskeleton and therefore cellular behaviour. On the other hand, decorin can bind soluble factors such TGF- $\beta$, regulating their biological activity. ${ }^{32-34}$ The diminished expression of decorin in Alzheimer's disease fibroblasts might have a strong effect on the interaction between the cell and the ECM. It would be interesting to determine whether the addition of purified decorin to these cells enhanced the adhesion phenomena. Because decorin has multiple functions, it would be intriguing to investigate whether the characteristics of the skin of Alzheimer's disease patients shows some degree of alteration. Experiments to determine the organisation of the skin as well decorin concentrations and/or their transcripts would be worth doing on skin from Alzheimer's disease patients. If such a change is observed it would be essential to determine when these alterations began and to understand whether these parallel the onset of the disease.

Apart from the possible consequences on fibroblast adhesion, as a result of altered proteoglycan synthesis, proteoglycans have a direct role in the formation of the typical amyloid containing plaques and neurofibrillary tangles in Alzheimer's disease. Decorin has been demonstrated in the periphery of amyloid containing plaques and neurofibrillary tangles of 
Alzheimer's disease ${ }^{35}$ while other proteoglycans and ECM molecules have been described in association with the plaques. $^{12}$ The direct interaction of heparan sulphate proteoglycans with $\beta$-APP has been shown both in vitro ${ }^{5}$ and in vivo ${ }^{\circ}$ after infusions of $\beta$-APP plus specific heparan sulphate proteoglycan, suggesting that heparan sulphate proteoglycans are key elements in the formation of amyloid plaques in Alzheimer's disease. Changes in proteoglycan synthesis may precipitate amyloid deposition in neurofibrillary tangles and the cerebrovascular system. Whether the decreased expression of decorin observed in Alzheimer's disease fibroblasts is characteristic of Alzheimer's disease fibroblasts or corresponds to altered cell adhesion is not known. Whatever the reason for the observed decrease in decorin synthesis, this type of study needs to be extended to other forms of Alzheimer's disease, such as sporadic Alzheimer's disease. If this observation is confirmed, it might represent a potential diagnostic marker. The fact that decorin is found in association with amyloid containing plaques in the brain raises interesting questions about the source of this proteoglycan in the central nervous system. In situ hybridisation experiments have shown that decorin is expressed in several cell types in the central nervous system, such as the spinal cord, the ventral horn motor neurons, neurons in grey matter, Purkinje neurons and cells of the molecular layer in cerebellum, and in neurons of the primary olfactory cortex and brainstem. ${ }^{36}$ Therefore, the exact source of decorin found in the plaques need not necessarily be attributable to fibroblasts and therefore it would be necessary to determine whether fibroblasts present in the central nervous system of Alzheimer's disease patients synthesise low concentrations of decorin as did the skin fibroblasts studied here.

We thank Dr Nibaldo C Inestrosa for his helpful comments. This work was supported by a grant from FONDECYT 1930565

1 Brandan E, Inestrosa NC. Extracellular matrix components and amyloid in neuritic plaques of Alzheimer's disease. Gen Pharmacol 1993;24:1063-8.

2 Fillit $\mathrm{H}$, Lewengle B. Disorders of the extracellular matrix and the pathogenesis of senile dementia of the Alzheimer's type. Lab Invest 1995;72:249-53.

3 Small DH, Nurcombe V, Reed G, Clarris H, Moir R, Beyreuther K, Masters CL. A heparin-binding domain in the amyloid protein precursor of Alzheimer's disease is involved in the regulation of neurite outgrowth. $\mathcal{f}$ Neurosci involved in the regula

4 Schubert D, LaCorbiere M, Saitoh T, Cole G. Characterization of an amyloid $\beta$ precursor protein that binds heparin and contains tyrosine sulfate. Proc Natl Acad Sci USA 1989;86:2066-9.

5 Narindrasorasak S, Lowery D, Gonzalez-DeWhitt P, Poorman RA, Greenberg B, Kisilevsky R. High affnity interactions between the Alzheimer's $\beta$-amyloid precurso proteins and the basement membrane form of heparan sulfate proteoglycan. $\mathcal{F}$ Biol Chem 1991;266:12878-83.

6 Snow AD, Sekiguchi R, Nochlin D, Fraser P, Kimata K, Mizutani A, et al. An important role of heparan sulfate proteoglycan (perlecan) in a model system for the deposition and persistence of fibrillar $\mathrm{A} \beta$-amyloid in rat brain. Neuron 1994;12:219-34

7 Joachim CL, Mori H, Selkoe DJ. Amyloid $\beta$-protein deposition in tissues other than brain in Alzheimer's disease. Nature 1989;341:226-30.
8 Glenner CG, Wong CW. Alzheimer's disease and Down syndrome: sharing of a unique cerebrovascular amyloid fibril protein. Biochem Biophys Res Commun 1984;122: $1131-5$.

9 Sims, NR, Finnegan JM, Blass JP. Altered metabolic properties of cultured skin fibroblasts in Alzheimer's disease. Ann Neurol 1987;21:451-7.

10 Takeda M, Tanaka M, Kudo T, Nakamura Y, Tada K, Nishimura T. Changes in adhesion efficiency and vimentin distribution of fibroblasts from familial Alzheimer's disease patients. Acta Neurol Scand 1990;82:238-44

11 Takeda M, Tatebayashi Y, Nishimura T. Change in the cytoskeletal system in fibroblasts from patients with familial Alzheimer's disease. Progr Neuropsychopharmacol Biol Psychiatry 1992;16:317-28.

12 Bernfield M, Kokenyes R, Kato M, Hinkes MT, Spring J, Gallo RL, Lose EJ. The biology of the syndecans. Annu Rev Cell Biol 1992;8:365-93.

13 Clark EA, Brugge JS. Integrins and signal transduction pathways: The road taken. Science 1995;268:233-9.

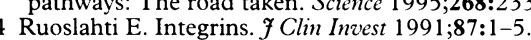

15 Hardingham T, Fosang AJ. Proteoglycans: many forms and many functions. FASEB $\mathcal{F}$ 1992;6:861-70.

16 Zebrower M, Beeber C, Kieras FJ. Characterization of proteoglycan in Alzheimer's disease fibroblasts. Biochem Biophys Res Commun 1992;184:1293-300.

17 Balin AK, Baker AC, Leung IC, Blass JP. Normal replicative life-span of Alzheimer's disease fibroblasts. Neurobiol Aging 1988;9:195-8.

18 Blass JP, Baker AC, Ko L, Sheu RK, Black RS. Expression of "Alzheimer antigens" in cultured skin fibroblasts. Arch Neurol 1991;48:709-17.

19 Brandan E, Fuentes ME, Andrade W. The proteoglycan decorin is synthesized and secreted by differentiated myotubes. Eur F Cell Biol 1991;55:209-16.

20 Campos A, Nuñez R, Koenig CS, Carey DJ, Brandan E. A lipid anchored heparan sulfate proteoglycan is present in the surface of differentiated skeletal muscle cells: Isolation and biochemical characterization. Eur 7 Biochem 1993;216: 587-95.

21 Melo F, Brandan E. Decorin is specifically solubilized by heparin from the extracellular matrix of rat skeletal muscles. FEBS Lett 1993;319:249-52.

22 Brandan E, Fuentes ME, Andrade W. Decorin, a chondroitin/dermatan sulfate proteoglycan is under neural control in rat skeletal muscle. $\mathcal{F}$ Neurosci Res 1992;32:51-9.

23 Krusius T, Ruoslahti E. Primary structure of an extracellular matrix proteoglycan core protein deduced from cloned cDNA. Proc Natl Acad Sci USA 1986;83:7683-7.

24 Glössl J, Beck M, Kresse H. Biosynthesis of proteodermatan sulfate in cultured human fibroblasts. $7 \mathrm{Biol}$ Chem 1984;259: 14144-50.

25 Roughley PJ, White RJ. Dermatan sulphate proteoglycans of human articular cartilage. Biochem $\mathcal{7}$ 1989;262:823-7.

26 Fisher LW, Termine JD, Dejter SW, Whitson SW, Yanagishita M, Kimura JH, Hascall VC, Kleinman HK, Hassell JR, Nilsson B. Proteoglycans of developing bone. 7 Biol Chem 1983;258:6588-94

27 Ruoslahti E. Proteoglycans in cell regulation. 7 Biol Chem 1989;264:13369-72

28 Takahashi T, Cho HI, Kublin CL, Cintron C. Keratan sulfate and dermatan sulfate proteoglycans associate with type VI collagen in fetal rabbit cornea. 7 Histochem Cytochem 1993;41:1447-57.

29 Font B, Aubert-Foucher E, Goldschmidt D, Eichenberger $D$, Van der Rest M. Binding of collagen XIV with the dermatan sulfate side chains of decorin. 7 Biol Chem matan sulfate side

30 Winnemoller M, Schmidt G, Kresse $H$. Influence of decorin on fibroblast adhesion to fibronectin. Eur $\mathcal{F}$ Cell Biol 1991 54:10-17.

31 Carey DJ, Stahl RC, Cizmeci-Smith G, RC, Asundi VK Syndecan-1 expressed in Schwann cells causes morphological transformation and cytoskeletal reorganization and associates with actin during cell spreading. $\mathcal{f}$ Cell Biol 1994 124:161-70.

32 Yamaguchi Y, Mann D M, Ruoslahti E. Negative regulation of transforming growth factor-beta by the proteoglycan of transforming growth factor-b
decorin. Nature 1990;346:281-4.

33 Hildebrand A, Romaris M, Rasmussen LM, Heinegard D, Twardzik DR, Border WA, Ruoslahti E. Interaction of the small interstitial proteoglycans biglycan, decorin and fibromodulin with transforming growth factor $\beta$. Biochem $f$ 1994;302:527-34.

34 Takeuchi Y, Kodama Y, Matsumoto T. Bone matrix decorin binds transforming growth factor- $\beta$ and enhances its bioactivity. F Biol Chem 1994;269:32634-8.

35 Snow AD, Mar H, Nochlin D, Kresse H, Wight TN Peripheral distribution of dermatan sulfate proteoglycans (Decorin) in amyloid-containing plaques and their presence in neurofibrillary tangles of Alzheimer's disease. $f$ Histochem Cytochem 1992;40:105-3.

36 Hanemann CO, Kuhn G, Lie A, Gillen C, Bosse F, Spreyer $\mathrm{P}$, Muller HW. Expression of decorin mRNA in the nervous system of rat. F Histochem Cytochem 1993;41:1383-91. 